\title{
1.12
}

\section{Ouvidoria Ativa do Ministério da Saúde: aprimoramento de uma gestão democrática}

Active Ombudsman at Ministry of Health (Brazil): enhancing democratic management

\section{Rebecca Lucena Theophilo}

Turismóloga. Especialista em Direito Sanitário. Colaboradora do Ministério da Saúde. Brasília, Brasil.

\section{Sandra Mara Campos Alves}

Advogada. Especialista em Direito Sanitário e Mestre em Política Social. Pesquisadora Colaboradora do Programa de Direito Sanitário, da Fundação Oswaldo Cruz. Brasília, Brasil.

Resumo: Dentre as competências da Ouvidoria do SUS, destaca-se a de implementar politicas de participação da sociedade para avaliação dos serviços prestados em saúde. Com esse intuito, o Ministério da Saúde implementa a Ouvidoria Ativa, cujo objetivo é buscar informações avaliativas junto aos cidadãos que realizaram procedimentos ambulatoriais de alta complexidade ou obtiveram autorização para internação hospitalar. A CartaSUS é o instrumento de contato entre a Ouvidoria e o cidadão, por meio do qual o usuário poderá avaliar o atendimento e os serviços prestados nos hospitais da rede pública de saúde e das unidades conveniadas, sendo o Disque Saúde, canal gratuito que atende pelo número 136, o principal canal de entrada dessas respostas.

Palavras Chave: Democracia sanitária; direito à saúde; ouvidoria.

Keywords: Health democracy; the right to health; ombudsman.

\section{Introdução}

A ouvidoria, no âmbito do Sistema Único de Saúde, é realizada por meio do Departamento de Ouvidoria Geral do SUS (DOGES), da Secretaria de Gestão Estratégica e Participativa do Ministério da Saúde. Entre suas competências destacase a de implementar políticas que estimulem a participação de usuários e entidades da sociedade na avaliação dos serviços prestados pelo SUS, de modo a contribuir para a melhoria da qualidade desses serviços, bem como fortalecer o papel do controle social exercido pelos cidadãos. 
Nesse sentido, a Ouvidoria Geral do SUS vai para além do papel clássico de ausculta passiva da sociedade, e inova propondo ações e estratégias de comunicação direta com a sociedade, reformulando o conceito e a dinâmica das ouvidorias.

O Ministério da Saúde no intuito de coletar dados para subsidiar a gestão na avaliação de programas, ações e serviços de saúde, implementa a Ouvidoria Ativa, cuja atuação é a busca de informações avaliativas junto aos cidadãos que utilizam o Sistema Único de Saúde, reforçando o controle e participação da população na gestão do SUS.

A CartaSUS, um exemplo dessa iniciativa, foi lançada em 2012 pelo Ministério da Saúde e tem como objetivo principal buscar informações sobre o atendimento dos cidadãos no sistema público de saúde ou na sua rede conveniada, por meio de dados obtidos da Autorização de Internação Hospitalar (AIH) e/ou Autorização de Procedimento Ambulatorial de Alta Complexidade (APAC).

Por meio da CartaSUS, o cidadão pode avaliar o atendimento e os serviços prestados nos hospitais da rede pública de saúde e das unidades conveniadas, conferir os dados correspondentes aos serviços prestados, acompanhar os custos da internação e serviços, e, inclusive, denunciar irregularidades, no caso de verificar dados não compatíveis. As avaliações obtidas são utilizadas para melhorias da gestão do SUS em todas nas três esferas de governo.

Em janeiro de 2012, o DOGES iniciou o envio da CartaSUS aos usuários que realizaram procedimentos no semestre anterior.

Um dos canais da Ouvidoria Geral do SUS - por meio dos quais podem ser recebidas as respostas da CartaSUS - é o Disque Saúde.

O Disque Saúde, segundo o Relatório Gerencial do DOGES, foi o canal mais procurado pelos cidadãos no ano de 2012, responsável por $52,2 \%$ dos registros da Ouvidoria, seguido pela internet (através do Formulário Web), com 41,7\%. Cartas corresponderam a 5,6\% e atendimento presencial, a 0,6\%.

O Disque Saúde é canal gratuito de comunicação que atende pelo número telefônico 136. Por esse meio, a população pode receber informações específicas sobre saúde e programas do Ministério da Saúde, além de registrar reclamações, denúncias, solicitações, sugestões e elogios. 
A democracia, como forma clássica de governo, tem como objetivo primordial resguardar a importância da participação política do cidadão nas decisões de Estado, diretamente ou por meio de seus representantes. Bonavides (2011) destaca que o exercício da participação popular redireciona a finalidade das atividades estatais, de modo a atender as reivindicações feitas pela sociedade.

Nesse sentido, é importante investigar a CartaSUS, à luz desse novo papel da ouvidoria, na busca pelo fortalecimento de uma gestão mais democrática e participativa.

\section{Metodologia}

Trata-se de uma pesquisa quali-quantitativa que utilizou, na coleta de dados, procedimentos de pesquisa documental.

A pesquisa documental foi realizada a partir dos dados armazenados no Sistema OuvidorSUS que, dentre outras funções, registra as manifestações dos usuários que serão encaminhadas aos ouvidores dos órgãos responsáveis pelas respostas aos cidadãos.

A cada extração de dados, o status da demanda pode ser distinto, pois comporta atualização. Assim os registros estudados foram obtidos em 03 de junho de 2013. Foram analisados os registros oriundos das respostas da CartaSUS recebidos por meio do Disque Saúde, no período de abril de 2012 a abril de 2013.

Por se tratar de banco de acesso restrito, a obtenção se deu através do Sistema de Eletrônico do Serviço de Informação ao Cidadão, com protocolo nº 25820.005394/2013-92.

\section{Resultados e discussão}

O Ministério da Saúde, quando idealizou o projeto da CartaSUS, estabeleceu um fluxograma de modo a definir os papéis de cada envolvido no processo (Figuras 1, 2 e 3).

A CartaSUS, além de informações sobre o procedimento realizado, traz cartão resposta com cinco perguntas relativas ao atendimento prestado pela equipe médica, ao atendimento prestado pela equipe de enfermagem, à maneira como foi tratado no hospital, ao estado das instalações físicas e questiona também se o cidadão recomendaria a unidade em que foi atendido para algum amigo ou familiar, no caso 
da CartaSUS AlH. Já na CartaSUS APAC, as perguntas são relativas às instalações físicas da unidade de saúde, ao atendimento dos profissionais de saúde que realizaram o tratamento, à maneira como o cidadão foi tratado e quanto à recomendação da unidade de saúde a um amigo ou familiar. 


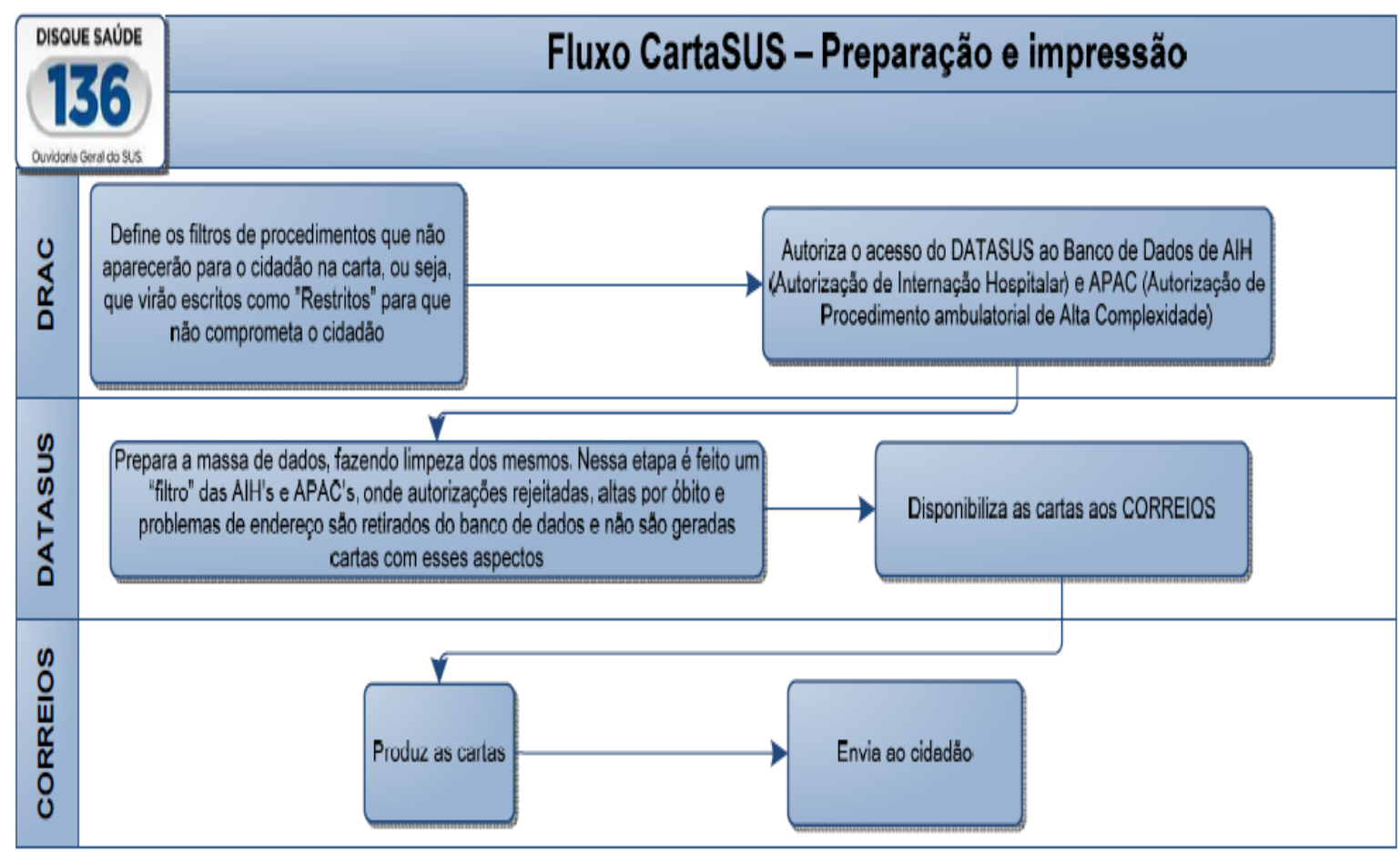

Figura 1 - Fonte: Site do Ministério da Saúde

http://portal.saude.gov.br/portal/saude/area.cfm?id area=1873 


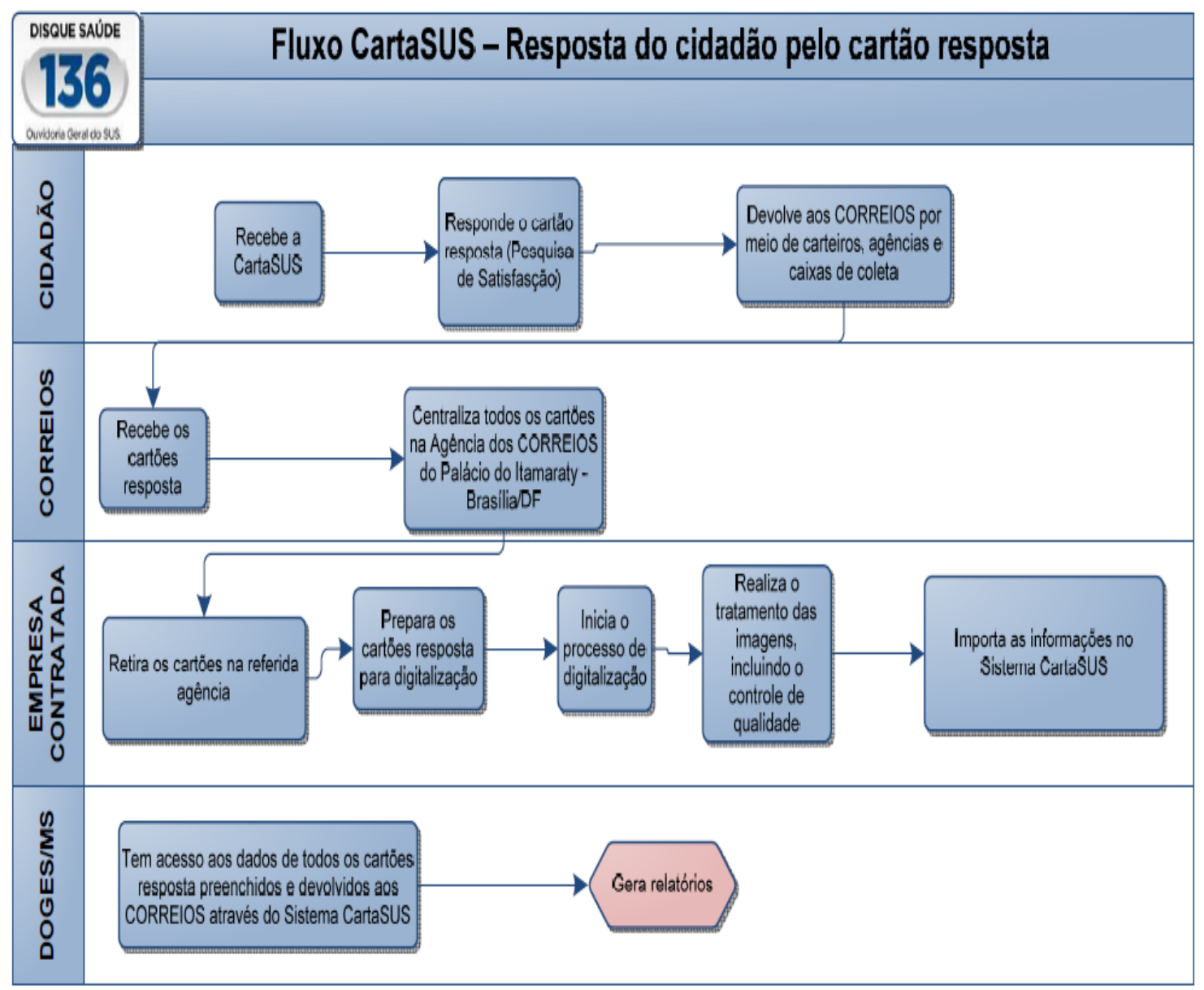

Figura 2 - Fonte: Site do Ministério da Saúde

http://portal.saude.gov.br/portal/saude/area.cfm?id area=1873 


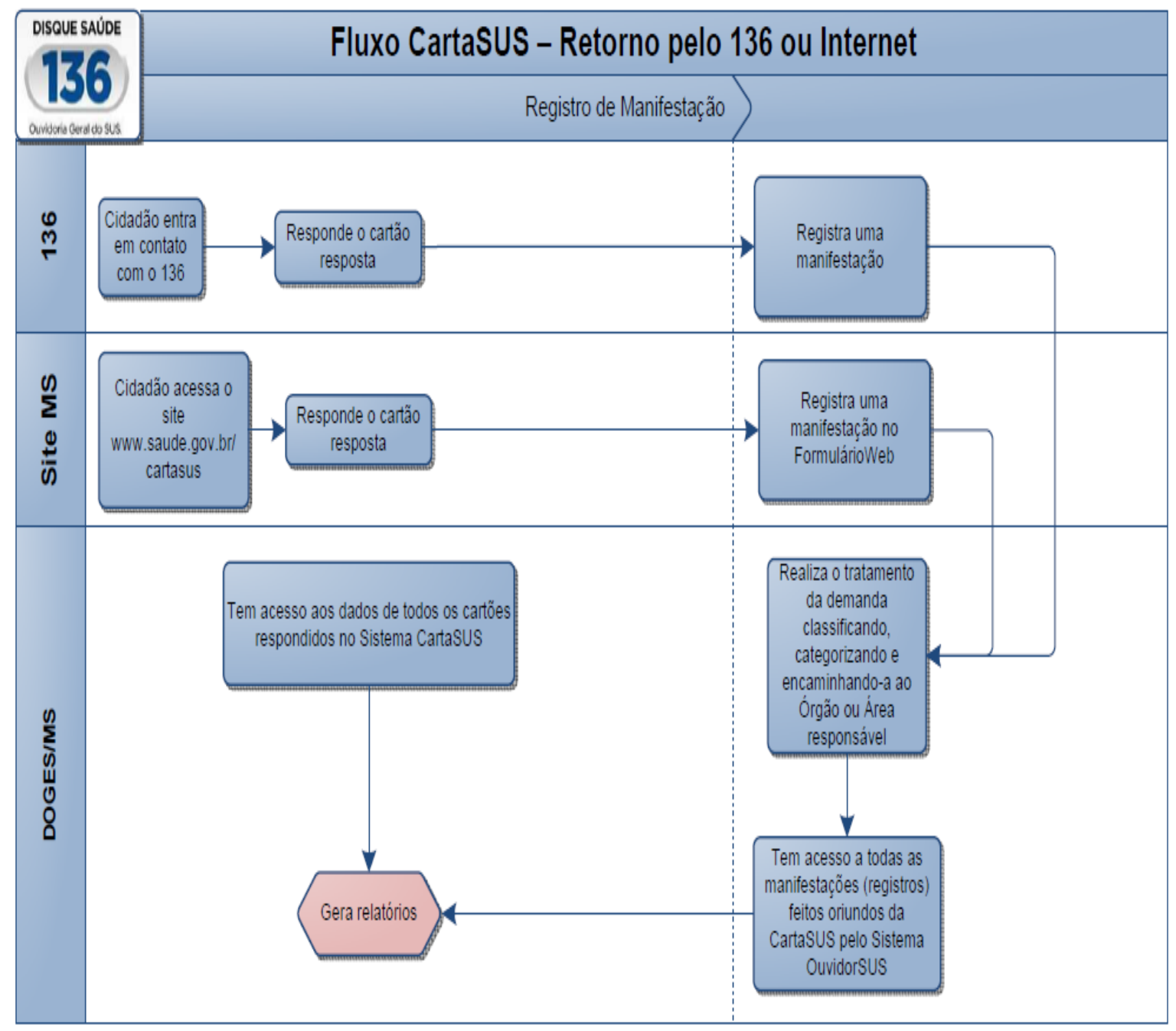

Figura 3 - Fonte: Site do Ministério da Saúde

http://portal.saude.gov.br/portal/saude/area.cfm?id area $=1873$ 
A CartaSUS foi responsável por 5,34\% registros no serviço de Ouvidoria no ano de 2012. O Disque Saúde foi o principal canal de entrada desses registros, com 3.047 demandas, seguido pela Carta, com 75 demandas, e o Formulário web, com 54 demandas.

Gráfico 1 - Demandas oriundas da CARTASUS, por meio de atendimento de abril 2012 a abril 2013.

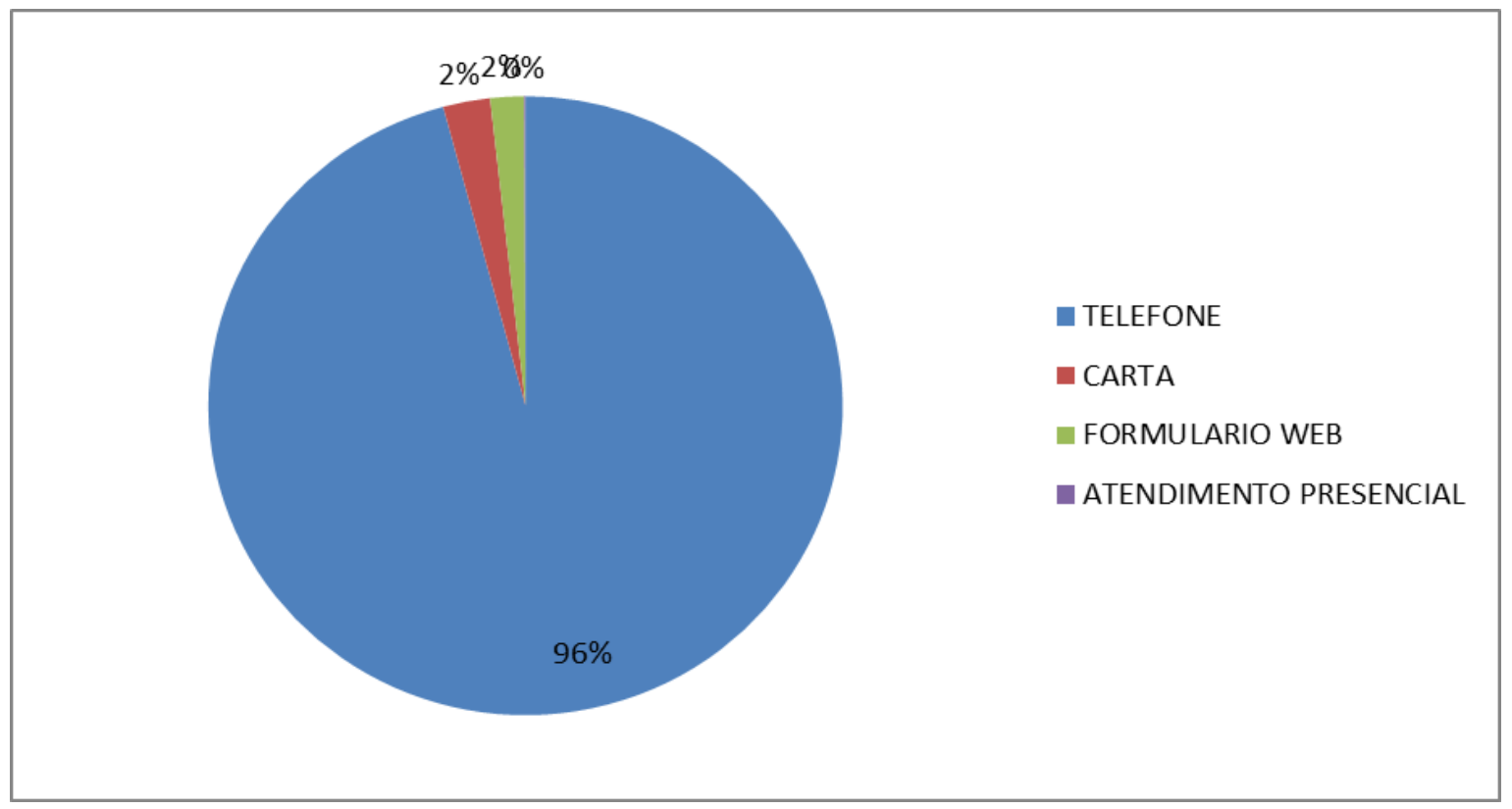

Fonte: Sistema OuvidorSUS/Datasus/Ministério da Saúde. Elaborado pelas autoras.

Todos os registros recebidos na Ouvidoria Geral do SUS são previamente classificados como: denúncia, reclamação, informação, solicitação, elogio e sugestão, observando o que dispõe o Manual de Tipificação do Sistema Informatizado OuvidorSUS.

De acordo com o referido documento, a denúncia ocorre quando há indicação de irregularidade ou indicio de irregularidade na administração e/ou atendimento por entidade pública ou privada. Já reclamação ocorre quando há insatisfação em relação às ações e aos serviços de saúde.

De forma distinta, a informação se vislumbra sempre que o cidadão faz questionamentos a respeito do sistema de saúde ou sobre assistência a saúde. A solicitação, embora possa indicar algum grau de insatisfação, se caracteriza principalmente por conter um requerimento de atendimento ou acesso às ações e aos serviços de saúde; 
Por fim, o elogio demonstra satisfação ou agradecimento por serviço prestado pelo SUS, e a sugestão propõe ação considerada útil à melhoria do sistema de saúde.

O Gráfico 2 apresenta o resultado das 3.047 demandas registradas no Disque Saúde relacionadas à CartaSUS, obedecendo a classificação estabelecida no Manual de Tipificação do Sistema Informatizado OuvidorSUS.

Gráfico 2 - Demandas oriundas da CARTASUS, segundo a natureza.

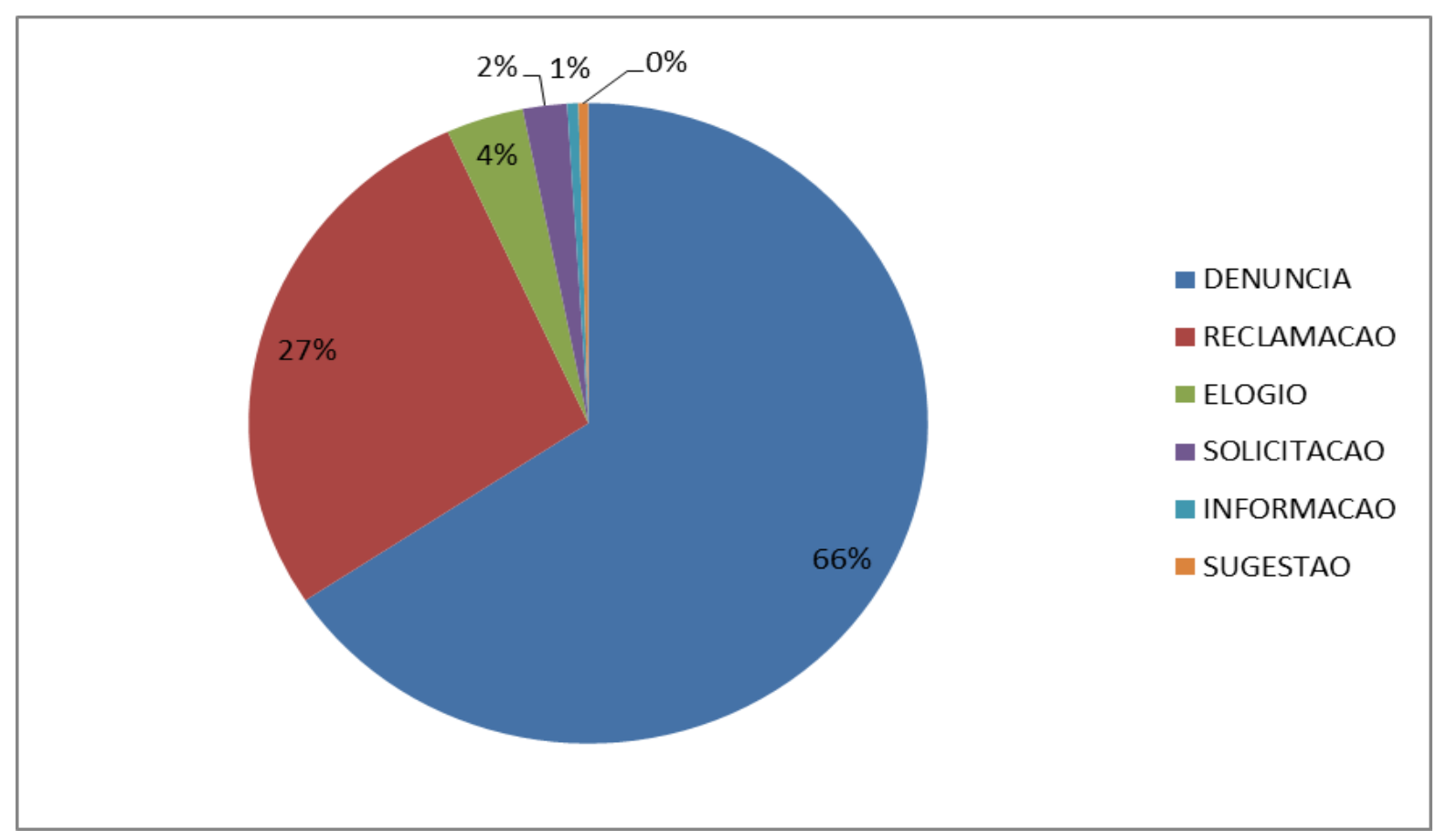

Fonte: Sistema OuvidorSUS/Datasus/Ministério da Saúde. Elaborado pelas autoras.

Ainda de acordo com o Manual de Tipificação, podemos avaliar os subassuntos de cada registro CartaSUS.

Assim, de 2.008 denúncias registradas, 1.149 foram sobre faturamento de procedimentos não realizados ou procedimentos divergentes do realizado pelo cidadão; 511 demandas foram sobre dados divergentes.

Dentre os subassuntos, destacam-se divergências sobre o período de realização do procedimento; 148 demandas referem-se a cobranças indevidas de procedimentos realizados, e 200, a um pequeno número de outros subassuntos. 
As reclamações se subdividem em: dados cadastrais divergentes, insatisfação com recursos humanos durante o atendimento realizado e sobre os estabelecimentos de saúde dentre outros.

Com a analise dos dados de classificação, observa-se a importância do papel fiscalizador que o usuário tem dentro da gestão do SUS e da CartaSUS como instrumento de participação do cidadão para que as melhorias aconteçam.

Dentre as competências do Departamento de Ouvidoria Geral do SUS, conforme art. 34 do Decreto nº 7.979/2012, está o de acionar os órgãos competentes para a correção de problemas identificados mediante denúncias e reclamações enviadas diretamente ao Ministério da Saúde, contra atos ilegais ou indevidos e omissões, no âmbito da saúde.

Assim, as demandas CartaSUS cadastradas no Disque Saúde são encaminhadas, na sua maioria, para as Secretarias Municipais de Saúde, para que apurem todos os dados, junto a sua rede de serviços, e tomar as providências necessárias, quando verificada a veracidade das informações.

Na Portaria ํo 08 de 25 de março de 2007, que regulamenta o Sistema OuvidorSUS, estabelece que, de acordo com o teor de cada manifestação, serão determinadas prioridades de baixa a urgente, e prazos máximos para conclusão de cada demanda, variando de 90 a 15 dias, a contar da data de seu encaminhamento para o órgão responsável.

Na data da extração dos dados (Gráfico 3), das 3.047 demandas registradas, 817 já haviam sido fechadas/arquivadas; 1.292 tinham sido encaminhadas ao órgão responsável para análise; 482 encontrava-se em análise por parte do órgão; e 174 estavam concluídas, com parecer para ser analisado pela Ouvidoria Geral do SUS que, após análise, fecha ou reencaminha a demanda para o órgão, caso ocorrido com 21 registros. 222 demandas encontra-se com status novo, pois ainda não tinham sido analisadas pelo técnicos do DOGES. 
Gráfico 3 - Status das demandas oriundas da CARTASUS

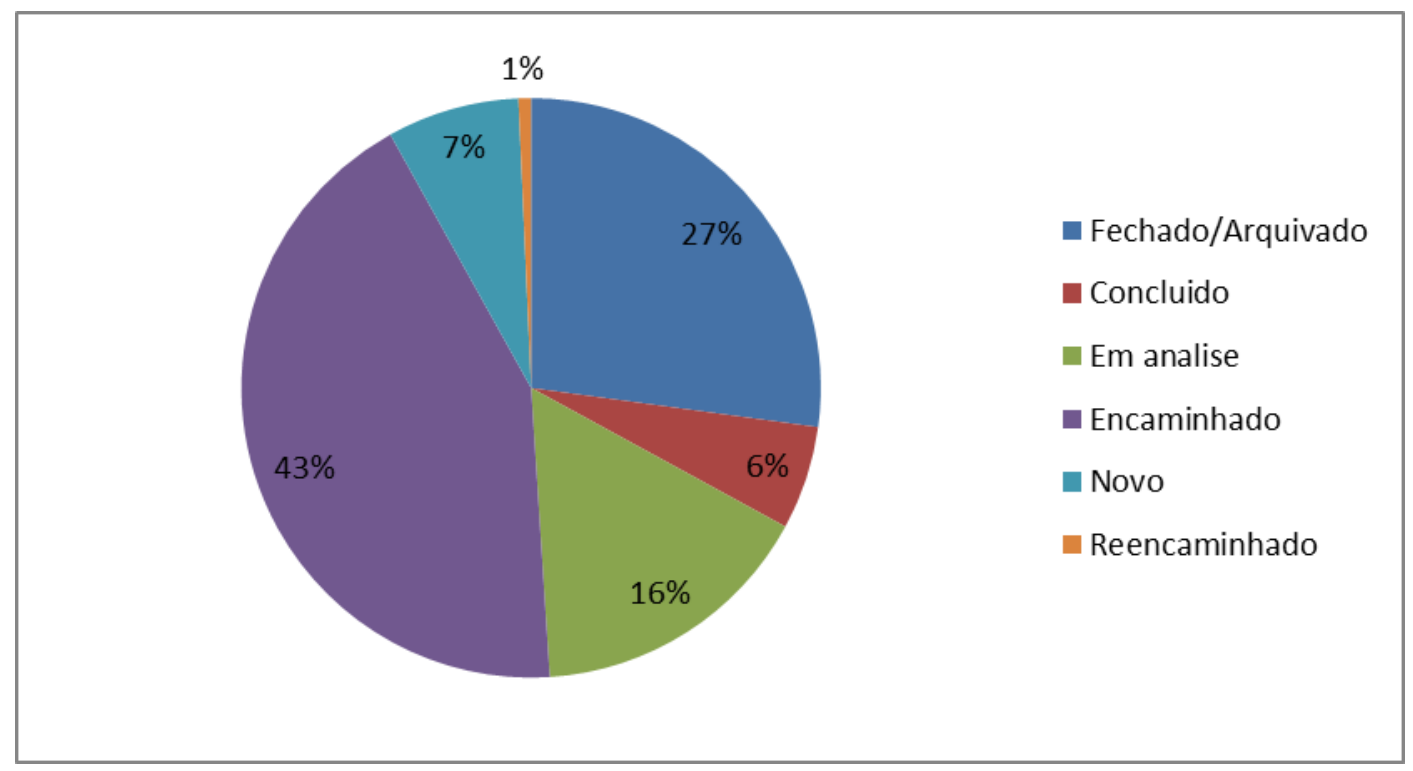

Fonte: Sistema OuvidorSUS/Datasus/Ministério da Saúde. Elaborado pelas autoras.

A CartaSUS é a legitimação da prática de cidadania, sendo uma ferramenta útil para planejar, monitorar, acompanhar e avaliar a gestão do SUS.

\section{Considerações finais}

A realização da democracia só é possível com a participação da sociedade e, nesse sentido, necessário se faz analisar as formas de gestão democrática possíveis.

A Ouvidoria Ativa representa um importante instrumento na Administração Pública Democrática, pois redimensiona o papel do cidadão na fiscalização das políticas públicas. Ademais, deixa de ser um órgão exclusivamente de escuta, que recebe queixas, reclamações e sugestões, para ter um papel protagonista e fortalecedor do controle social.

\section{Referências}

BONAVIDES, Paulo. Ciência Política. São Paulo: Malheiros, 2011.

BRASIL. Ministério da Saúde. Usuários vão avaliar qualidade das internações hospitalares, 2011. [online] Disponível na internet URL: http://portalsaude.saude.gov.br/portalsaude/noticia/3506/162/usuarios-vao-avaliarqualidade-das-internacoes-hospitalares.html (Consultado em 10.07.13).

BRASIL. Ministério da Saúde. Relatório Gerencial 2012. [online] Disponível na internet

URL: 
http://portal.saude.gov.br/portal/arquivos/pdf/relatorio gerencial 2012.pdf (Consultado em 02.09.2013)

BRASIL. Ministério da Saúde. Manual de Tipificação 2011. [online] Disponível na internet

URL: http://portal.saude.gov.br/portal/arquivos/pdf/manualdetipificacao ouvidoria 2012.pdf (Consultado em 02.09.2013)

BRASIL. Ministério da Saúde. Secretaria de Gestão Estratégica e Participativa. Departamento de Ouvidoria Geral do SUS. Falando de Ouvidoria: experiência e reflexões. Brasília: Ministério da Saúde, 2010.

BRASIL. Ministério da Saúde. Secretaria de Gestão Participativa. Departamento de Ouvidoria Geral do SUS. Oficina de Ouvidorias do SUS. Brasília: Ministério da Saúde, 2010.

CARDOSO, Antônio Semerado Rito. Ouvidoria como instrumento de mudança. Brasília: IPEA, 2010. 